\title{
Sexually transmitted diseases in the Republic of Ireland
}

\author{
R D CATTERALL \\ From the Department of Genitourinary Medicine, James Pringle House, Middlesex Hospital, London
}

Ireland is one of the British Isles, lying to the west of Great Britain from which it is separated by the Irish Sea. The Republic of Ireland is a sovereign independent state and occupies the larger part of Ireland. The country came into existence in 1922 as the Irish Free State with dominion status in the British Commonwealth. In 1937 De Valera introduced a new constitution in which Eire was declared a sovereign, independent, democratic state under a president. When J A Costello and his government passed legislation which took the Republic of Ireland outside the Commonwealth in 1949, the British Government also passed legislation which maintained for Irish citizens in the United Kingdom most of the advantages of British subjects, and a free trade area with the United Kingdom was established in 1966. Membership of the European Economic Community since 1973 has stimulated commercial expansion and the standard of living has risen appreciably in recent years. The population of Eire in 1981 was just over $31 / 2$ millions, of which the largest concentrations are in the Dublin area and in Cork in the south-west.

\section{Health service administration}

Eire has a modified type of national health service, and free medical attention is available to all Irish citizens whose income is below a certain level. Infectious diseases are usually treated without charge. There is, however, a well-developed private sector and private health insurance is growing in importance.

The health service is headed by the Minister of Health, who is a member of the Cabinet, and the country is divided into eight health boards for administrative purposes. The two largest health boards are the Eastern with a population of about $11 / 4$ million people, which includes Dublin and the surrounding area, and the Southern Health Board embracing Cork and its surrounding country with a population of over 500000 inhabitants.

Address for reprints: Dr R D Catterall, Department of Genitourinary Medicine, James Pringle House, Middlesex Hospital, London W1A

Accepted for publication 9 August 1982

\section{Sexually transmitted diseases}

Clinics for patients with certain venereal diseases were established in 1930 after accession to the Brussels Agreement on facilities for merchant seamen for the treatment of venereal diseases under the auspices of the League of Nations and later the World Health Organisation. This agreement made it mandatory for the member nations to provide special clinics where treatment was free and confidential at all the major sea and river ports of the country. Clinics were established in some of the larger hospitals in towns such as Dublin, Cork, Wexford, and Galway and were staffed by parttime doctors who treated sailors with syphilis, gonorrhoea, and chancroid, many of whom were peripatetic and moved on to other ports with their ships. The clinics were usually hidden away in basements or at the back of the hospitals as the subject evoked embarrassment and guilt feelings in the doctors and administrators more frequently than among the patients.

The rapid growth and evolution of air travel and the corresponding decline in sea travel after the second world war was not matched by appropriate changes so that modernisation of the VD clinics did not take place. Moreover, the changes in attitudes towards sex and the alterations in sexual behaviour, which occurred during the 1960s and 1970s, resulted in a great increase in the incidence of sexually transmitted diseases and the discovery that many more diseases were spread by the sexual route. Unfortunately, once again appropriate steps were not taken to meet this new threat to the health and well-being of young people, and the service for patients with sexually transmitted diseases has remained inadequate, rudimentary, and out of date.

Accurate figures are not available for the incidence of any of the sexually transmitted diseases owing to the absence of reporting and, as is usually the case in such circumstances, there is a tendency to minimise the size of the problem. There is increasing evidence, however, that the incidence of most of the sexually transmitted diseases is similar to that in other countries of comparable size and is increasing steadily with the development of air travel and the evolution of the tourist industry. 
Such information as is available indicates that the majority of patients with infections are seen in the private sector, usually by general practitioners. In Dublin there are some part-time clinics at the Mater Misericordiae Hospital, Sir Patrick Dun's Hospital, and Doctor Steeven's Hospital. In Cork there is a parttime clinic at St Finbarras Hospital for one session weekly. Elsewhere most patients are probably seen privately, often by doctors with no special training in the subject, usually without any microbiological or serological back-up and a total absence of contact tracing.

It is now widely recognised that sexually transmitted diseases have become the most rapidly expanding specialty in modern medicine. The correct management of patients with these diseases depends basically on proper teaching of undergraduate medical students, regular postgraduate up-dating of knowledge, suitable clinic facilities, good quality microbiological and immunological support services, and effective contact tracing. In the longer term medical research and health education of the public have an important role to play.

A community or country which does not have a modern up-to-date service for patients with sexually transmitted diseases might be considered to be a bad neighbour because it will have a high incidence of undiagnosed and untreated infection, some of which may be due to antibiotic-insensitive agents. A bad neighbour is a country which has no reliable figures of cases of infection so that the size and importance of the problem is not recognised. It is often a country where there is easy access to antibiotics without a prescription resulting in frequent self-treatment. As the specialty will not be properly recognised there will be no career structure for doctors and no postgraduate training schemes. Worse still there will be inadequate or non-existent teaching of medical students and nurses, and recruitment to the subject will be poor. Contact tracing will be rare and often ineffective, and there will be no research and, therefore, no new ideas but only stagnation.

\section{Recommendations for the future}

It has been clearly established that a well-developed service for patients with sexually transmitted diseases results in a lower rate of infection and a greatly diminished incidence of complications. ${ }^{1}$ Such a service is an important aspect of primary health care, as patients have direct access to highly skilled medical attention in the clinics. The reduction in the number of complications, such as pelvic inflammatory disease, also has important economic implications for the health service.

It is recommended by the Department of Health and Social Security in England that there should be one specialist in sexually transmitted diseases for every half million of the population. Based on this estimate there should eventually be six consultants in this specialty for the whole of Eire, with two in Dublin and one in Cork. A start might be made to establish a modern service by appointing one whole-time, fully trained physician in Dublin with responsibility for the establishment of an up-to-date service for the whole country. A second consultant and adequate supporting staff of nurses, receptionists, and secretarial staff would be appointed later. Because of the importance of high quality laboratory investigations one of the laboratories should be nominated as a reference laboratory to establish and maintain standards of work and to provide opportunities for audit and quality control.

Lastly, the development of a contact tracing service and the training of individual contact tracers should receive careful attention. The experience of health workers in the United Kingdom, together with the Handbook on Contact Tracing in Sexually Transmitted Diseases, ${ }^{2}$ might be helpful in the early stages.

The recent general assembly of the International Union against the Venereal Diseases and Treponematoses in Dublin in June 1982 stimulated considerable interest in the subject and has provided an excellent opportunity for a start to be made in the establishment of a modern service for sexually transmitted diseases. Membership of the European Economic Community has produced a chair at the Monospecialty Committee of Dermatovenereology of the European Union of Medical Specialists, where it is hoped that the voice of Ireland will be heard in the future with constructive suggestions for national and international control of the sexually transmitted diseases.

\section{References}

1. Catterall RD, Nicol CS. The service for sexually transmitted diseases in the United Kingdom. $J A M A$ 1975;2:8-12.

2. Hunter I, Jacobs J, Kinnell H, Satin A. Handbook on Contact Tracing in Sexually Transmitted Diseases. London: Health Education Council, 1980. 